as in the lives of so many English men of science. Brought together in the world's metropolis, we read not so much of isolated reflections in the quiet study as of familiar intercourse in the brotherhood of congenial tastes. After the death of Banks, in 1820, Rennell was the acknowledged head of English geographers. Travellers and explorers came to him with their rough work, projects were submitted for his opinion, reports were sent to him from all parts of the world. The Raleigh Club was formed in 1827, 'for the attainment at a moderate expense, of an agreeable, friendly and rational society, formed by persons who had visited all parts of the world.' After Rennell's death the formation of a Geographical Society to supply his place became a necessity, and thus largely from his impulse was founded what has become the greatest force in geography to-day. Exploration rather than explanation was then naturally the direction of earth study; and it is chiefly in this division of geography that the English still follow their leader. W. M. D.

Oeuvres ophtalmologiques de Thomas Young, traduites et annotées par M. Tscherning, précédées du portrait de Young, de son élogue par François Arago et d'une préface par EMILE JAval. Publication faite aux frais de la Fondation Carlsberg. Copenhague, Höst et Son. 1894.80 pp. $x+248$.

Among the great men who have inaugurated important epochs in science there are two classes; the first, writing with a fertile imagination and extraordinary capacity for work, have developed one or more kindred ideas and have achieved results of great perfection; the second class, while endowed with imagination no less, or perhaps even more powerful, have, in the absence of persistent, concentrated effort, followed the caprices of an intellectual curiosity which led in divers directions, and the works of their genius which have been preserved are consequently less perfect both in form and substance. Their writings are often intricate and obscure; but this very complexity not infrequently invests them with a peculiar charm for the thinker.

The most distinguished of the first type of mind was Isaac Newton; the most remarkable of the second type was Thomas Young. Newton turned all the efforts of his genius toward mathematics and physics. To facts carefully observed he applied the powerful aid of the calculus and gave one of the finest examples of the fecundity of the mathematical method. The works of Laplace, Ampère, Cauchy and, in a certain measure, those of Fresnel are the product of a similar spirit. Works of this class are usually crowned with recognition and honors during the lifetime of their authors; for sooner or later, by the force of logic, they are able to rise above the never-failing hostile coalitions of mental inertia and the vanity of mediocrity in power. The same good fortune, however, is not the part of such works as those of Thomas Young. Mathematician, physicist, naturalist, physician, philologist and engineer, he has left profound traces of his originality in each of these domains; yet in not one of them was his genius recognized by his contemporaries. Endowed with extraordinary intuitive power, he was able to assimilate with marvellous rapidity the most varied kinds of knowledge, the consequence of which marks all his writings with a conciseness of language and exposition which, for the ordinary student accustomed to long and minute reasoning, gives to them an obscurity ofttimes discouraging.

The complications of Nature are infinite, and never in her manifold manifestations does she take into account the categories among which our intelligence is forced to divide itself up both in methods and reasoning. There is not a phenomenon in the animate world which has not its characteristics at once physico-chemical and mathematical; and the stating of biological problems in the form of problems in physics accessible to mathematical calculation is always attended with great difficulty. Young treated biological problems, especially those of ophthalmology, in this spirit, which was not then, and is not now, that of the medical profession. As a natural result he was not understood by his confrères, or was understood only sufficiently to be considered their adversary; an attitude by no means calculated to enhance his scientific popularity. He had besides the honor of being able to furnish an elegant interpretation of the curious phenomenon of the coloration of soap-bub- 
bles and other thin transparent substances; also he explained phenomena not previously known, such as the shadow produced on a screen by the superposition of two luminous rays proceeding from the same source and arriving at the same point by different routes of unequal length ; or, again, the augmentation of light which appears periodically when the differences of the respective routes vary. He saw that these facts were admirably explained by the hypothesis of undulations in an imponderable medium which, according to the concordance or discordance of their periods, mutually added to or destroyed each other; an hypothesis, it will be seen, diametrically opposed to that advanced by Newton. Notwithstanding his endeavor to place his idea under the patronage of his illustrious predecessor, the theory of interferences was denounced as sacriligious by powerful adversaries, who held the public conscience and who never relinquished their hostile attitude.

But Young was ' not without honor save in his own country;' the recognition denied him in England has, thanks to a happy accident, been freely accorded in France. It was at the hands of the great Arago, himself interested in optics, that he received his first encouragement, followed by academic honors. In any case, it is in the works of Fresnel, who was inspired by the same principle, that Young's achievements were for the first time crowned with approbation; and it was the experiments of Foucault on the rapidity of the propagation of light through air and through water which gave the fatal blow to the emission theory and secured for the theory of interference a final victory. For some time past the physicists have shown a certain indifference concerning the undulatory and molecular theories, doubtless because of the superficial generalization built upon these theories twenty years ago. We cannot refuse to them, however, in spite of their hypothetical character, a marvellous rôle in discovery (as, for instance, the experiments of Herz on electrical undulation) as well as a system of representation quite satisfactory to the mind which does not seek to make a universal application. However this may be, Young has other claims to the admiration of physicists, as, for instance, the first efforts made to unite by an empirical formula the elastic forces of vapors and their temperatures.

The works of Young in ophthalmology have not attracted the attention they merit, notwithstanding the liberal recognition of their results on the part of Helmholtz and Donders. Maxwell, Helmholtz and Rood have popularized his theory of colors which consists in attributing to the retina three kinds of fibres responding respectively to the three fundamental colors: red, green and violet; and producing by their combined impression the sensation of all the other colors; in like manner the combination of these three primary colors in variable proportions is able to produce all the appearance of colors. This hypothesis admits but a single mode of transmission of the impression through the nerves to the brain. It makes the differentiation of the sensation of color consist in a functional modification of the periphery rather than in a cerebral operation. But, while it offers a plausible explanation of certain cases of color-blindness, this theory is far from having obtained general acceptance. It seems difficult to apply it to the explanation of those cases of color-blindness where but a single color is perceived and that different from the fundamental colors of Young. But it must be admitted that Young did not advance his hypothesis without reserve, and the theories which have since undertaken to supersede his are scarcely more satisfactory; they are not susceptible of any better experimental proof nor of theoretical deductions.

A distinguished ophthalmologist, M. Tscherning, has just published a French translation of Young's works on ophthalmology with liberal commentary. The subjects therein treated appear in the following order:

1. Observations on Vision. (Philos. Trans. for 1793.)

2. A memoir 'On the Mechanism of the Eye.' (Philos. Trans. for 1801.)

3. Extracts on the vision of colors taken from different essays.

4. The 38th chapter of Lessons on Natural Philosophy, London, 1807: On Vision.

'Observations on Vision' were written at the age of twenty and present many remarkable re- 
flections; take, for instance, this idea (which is developed by Chevreul in his voluminous volume On the Law of the Simultaneous Contrast of Colors) that those colors which, when combined, approach the nearest to white, produce, when placed side by side, the most agreeable effect. This opinion regarding the complementary colors is too absolute, as has been shown by a number of recent works; but it is a first step in the science of the harmony of colors.

The lesson 'On Vision' terminating the work is a brilliant résumé of the knowledge of that time, together with the writer's personal ideas on the subject of ocular dioptrics, showing from the point of view of design in Nature all the advantages of the optical construction of the eye. The eye, as we know, is a sort of camera obscura, at the back of which is the retina. Before reaching the retina the luminous ray must pass through an ensemble of transparent media, which offers all the advantages of the convex lens without its inconveniences. We know, furthermore, that the luminous rays which strike the margins of the lens have their focus or point of meeting in advance of the focus formed by the rays which penetrate the center of the lens, to obviate which disturbing feature in photographic instruments a diaphragm is devised which cuts off the marginal rays. The iris of the eye, that membrane with its constantly contracting and expanding circular opening, placed in front of the crystalline, .exercises the same function. Young shows how Nature aids still further in this direction by giving to the crystalline a gradually increased density from surface to center, thanks to which the focus of oblique rays is made almost to coincide on the entire concave surface of the retina.

The mémoire 'On the Mechanism of the Eye' is the most important of the work ; it is remarkable for the complexity of means employed. The laws of refraction in media of uniform density had long been known; the author shows how the total index of refraction of a lens varies according to the index of refraction at the surface, when the density of the sphere or the lens varies according to the power of the distance between the surface and the center. This applies to the crystalline. He shows that the total index of the lens is greater than the index of the center when the index, as in the case of the crystalline, is greater for the center than for the exterior. The number he got for the total index was found almost precisely correct by Mathiesen. It is in this same mémoire that appears for the first time a description of the Optometer with which Young made his principal determinations, the most complete that have ever been made of a single eye; but the instrument never came into general use and the translator was unable to find any trace of it. The principle upon which it was constructed (by Scheiner) is of a simplicity truly remarkable; a straight line down an oblong cardboard, and an ordinary visiting card perforated at one end with two pin holes, will give a fair idea of this ingenious device. By closing one eye and placing the other at the pin holes, which are held at one end of the straight line, the line in question appears no longer as a single line. To the eye looking through the pin holes two distinct lines present themselves which gradually tend one toward the other till they meet, and their point of meeting constitutes the nearest point of distinct vision. Any one may possess this simple contrivance home-made ; by a system of graduation on the cardboard one may readily obtain a correct measurement of the position of the eye's focus. The experiment will show how difficult it is to fix the point where two lines cross, and the reason is that it requires considerable practice to be able to place one's eye in perfect repose, $i$. e., to paralyze its accommodation.

Young had a large, prominent eye; which last feature he utilized with a compass to obtain an exact measurement of its length, which he found to be $23.11 \mathrm{~mm}$. It was with his optometer that he discovered astigmatism, the unequal refracting power of the eye in different meridians; the exact degree of which he measured by the focal distance of the lens adapted to its correction. This visual defect he here speaks of for the first time, but without seeming to attach to the discovery any special importance. Young presents very complete no. tions on the following subjects: the field of vision; the field of perfect vision; the sensibility of the retina, less at the fovea than at 
the periphery; on the field of regard; the fitness of the form and place of the retina for the production of a distinct image; the power of dispersion by the eye for different colors. Finally he takes up the famous problems of the mechanism which produces accommodation. To produce a distinct image of a given object on a screen the lens must be placed at a certain fixed distance from the object; how is it then that the screen known as our retina is able to receive distinct images at different distances? This problem is one not yet solved in all its complexity. The explanation offered by M. Tscherning is that the alteration required in the crystalline to form an image of objects near by is produced by the tension of the borders of the crystalline, thus increasing the convexity of the center. This is also Young's idea. Helmholtz sought to explain the alteration of the crystalline by an entirely different mechanism. Before entering upon the subject Young undertakes to eliminate the various other causes which might be invoked in elucidation of the problem. To prove that the cornea bears no part in accommodation, he neutralizes its refracting power by immersing it in water and substituting in its place a lens, and observes that there is no change in the range of his accommodation. One cannot but be struck with admiration for the patience and ingenuity which such an operation supposes. The decisive argument in favor of a change of form in the crystalline is derived by Young from a fact which Wollastan and Helmholtz sought in vain to verify, but which is verifiable on the eyes of youth, i. e., the correction of the aberration during accommodation. His determination of the nature of crystalline alteration was due to another fact which has just recently been verified-that the capacity of accommodation is half as much again greater at the center of the crystalline than at its periphery; from which he concluded a flattening of the surfaces at the periphery.

It will be seen by this brief review to what an extent the ideas of Young on ophthalmology are still fresh and of absorbing interest; more than any other he has prepared the way for the final solution of these problems.

\section{Charles Henry.}

PARIS.
SOCIETIES AND ACADEMIES.

THE ENTOMOLOGICAL SOCIETY OF WASHINGTON.

THE 110th regular meeting was held October $10,1895$.

Mr. Hubbard read a paper entitled 'Additional Notes upon the Insect Guests of the Florida Land 'Tortoise,' in which he gave his observations of the past summer, including a number of facts supplemental to his article on this subject published in Insect Life, Vol. VI., No. 4. The list of regular inhabitants of the burrows of the Florida land tortoise now reaches 19 species, of which 18 are insects and one is a vertebrate (Rana osopus). Aside from these, 5 insects are constant visitors to the burrows. The paper was briefly discussed by Messrs. Schwarz and Gill. Mr. Schwarz referred to the possible finding of a similar insect fauna in the burrows of the European Testudos and of the two other American species of Gopherus. Dr. Gill showed that the European species do not make burrows, and argued that in spite of the close resemblance of American forms to the Florida species we must not necessarily assume that they are burrowers. Mr. Schwarz said that the inhabitants at Penas, a station on the Mexican National Railway, near Laredo, informed him that there is a burrowing tortoise in the great sand plains near that place. This he thinks may be G. berlandieri.

Mr. O. F. Cook made some general remarks under the head 'Insect Collecting in Africa,' describing some of the rarities which he had found, giving in some detail his impression of the insect fauna of Liberia, and describing his experience with driver ants. These insects, he thinks, may be responsible for the almost total absence of snakes in Liberia, since when snakes are gorged with food they are motionless and defenseless and are easy prey for these active and voracious ants. Mr. Schwarz remarked that no trace of a more or less permanent nest of Eciton has ever been found, and the queen is not known. These ants make temporary nests and are in the main peripatetic. The fact that we do not know the queen, however, argues that a true nest will some day be found. $\mathrm{He}$ called attention to the fact that the Rev. P. Jerome Schmidt has found a species of Eciton in North Carolina. 